\title{
EFFECTS OF THE INTRAVENOUS ADMINISTRATION OF GLYCEROL SOLUTIONS TO ANIMALS AND MAN ${ }^{1}$
}

By HENRY A. SLOVITER with THE TEChNICAL ASSISTANCE OF RITA M. TIETZE

(From the Harrison Department of Surgical Research, School of Medicine, University of Pennsylvania, Philadelphia, Pa.)

(Submitted for publication August 6, 1957 ; accepted January 10, 1958)

It has been found that human erythrocytes can be stored in the presence of glycerol at below-freezing temperatures for long periods of time (1) and that subsequently they can be successfully transfused (2). The development of a method (3) which permits the transfusion of thawed erythrocyte-glycerol mixtures, without completely removing the glycerol, has led to the present investigation, whose aim was to determine the effects of the intravenous administration of glycerol solutions and particularly to determine whether glycerol can be safely administered intravenously to human subjects.

The glycerol molecule is a part of the neutral fat (triglyceride) molecule and is, therefore, a substance which animals and humans normally metabolize. It is known that glycerol is converted by the liver to glycogen and other carbohydrates (4). Several studies have shown that large quantities of glycerol can be administered orally to experimental animals and man without the appearance of adverse effects (5-8). However, there have been reports that the parenteral administration of glycerol to experimental animals has been followed by hemoglobinuria (9-11), hypotension $(5,12)$, central nervous system disturbances $(12,13)$, and weight loss (14). In the only reported instance of the parenteral administration of glycerol to man, no toxic effects were noted after the administration of very small quantities via artery or vein (15). In most cases where toxic effects have been reported to follow the parenteral administration of glycerol, the toxic effects have been more frequent and more pronounced after subcutaneous, than after intravenous administration.

The present investigation deals with the intravenous administration of glycerol solutions to the rabbit, the dog and to man. The results of this

1 Supported by a grant (H-1220) from the National Heart Institute, National Institutes of Health, United States Public Health Service, Department of Health, Education and Welfare. investigation show that a considerable quantity of glycerol in a relatively dilute solution containing electrolyte can be administered intravenously to man without producing any noxious effects.

\section{MATERIALS AND METHODS}

Glycerol solutions. Merck analytical reagent grade glycerol was used directly without further purification. Solutions containing approximately 5 per cent glycerol, 5 per cent glucose, and 0.9 per cent sodium chloride were used for the human infusion studies, because these are the approximate concentrations of these substances in the erythrocyte-glycerol mixture which is produced when a previously frozen erythrocyte-glycerol mixture is prepared for transfusion (3). This solution was prepared by adding $50 \mathrm{Gm}$. of glycerol to $1,000 \mathrm{ml}$. of sterile 5 per cent glucose in 0.9 per cent sodium chloride solution and then autoclaving the solution for 20 minutes at 15 lbs. steam pressure. For the experiments with rabbits and dogs, solutions of this same composition as well as others described below were used.

Rabbit experiments. Unanesthetized albino rabbits weighing between 2 and $3 \mathrm{Kg}$. were used. Solutions containing approximately 5 per cent glycerol in addition to electrolyte and glucose were infused via an ear vein. Rectal temperatures were measured before, during and after each infusion. Samples of urine voided during the course of the infusion, and the first urine voided after the infusion were collected in each case. In some cases, samples of urines which were voided on the following day were also collected. All urine samples were tested for the presence of hemoglobin by the benzidine test (16).

In two experiments, blood samples from an incised ear vein were collected in a tube containing heparin for the determination of plasma hemoglobin concentrations. Samples were obtained before infusion, when 10 per cent and 90 per cent of the solution had been infused, and 30 minutes and approximately 20 hours after the completion of the infusion. The blood samples were promptly centrifuged, plasma was removed and the hemoglobin concentration measured as described below.

In all experiments, the animals were carefully observed during the infusion period and for a short time thereafter for the appearance of muscle tremors, abnormal pupillary reactions or any behavior which might indicate central nervous system irritation.

Dog experiments. Dogs were anesthetized with pen- 
tobarbital (35 mg. per Kg.) and kymographic recordings of respiration and arterial blood pressure (from a cannulated carotid or femoral artery) were made. Solutions of various glycerol concentrations were infused via a cannulated femoral vein. Urine samples were collected during the course of the experiment and were tested for hemoglobin.

To determine whether the effects observed might be due to actions on the central nervous system, glycerol solutions were injected directly into a carotid artery, both before and after cutting the vagus nerves. Injections were also made into the descending aorta via a polyethylene catheter which had been inserted into the left carotid artery and advanced down the aorta to about the level of the diaphragm.

Human experiments. Hospitalized patients who were in a stable state and showed no functional abnormalities of their cardiorespiratory, urinary or central nervous systems were infused intravenously with the glycerol solution. Nearly all the human subjects had malignant disease and were considered to have quite limited life expectancies. In each case, $1 \mathrm{~L}$. of solution containing $50 \mathrm{Gm}$. of glycerol, $50 \mathrm{Gm}$. of glucose and $9 \mathrm{Gm}$. of sodium chloride was infused, except that in a few cases the salt was omitted. The duration of the infusion varied from three to six hours.

Immediately prior to infusion, pulse rate, respiratory rate, blood pressure, and oral temperature were measured. During the course of the infusion, pulse rate, respiratory rate and blood pressure were measured every 15 minutes for the first hour and thereafter every $30 \mathrm{~min}$ utes and again shortly after completion of the infusion. Temperature measurements were made at least twice during and once after completion of the infusion. The patients were carefully observed for any change in status, and were asked if they experienced any unusual sensations during the course of the infusion. A urine sample was obtained before the start of the infusion, and one or more samples were obtained during its course, and the first urine voided following the administration of the glycerol solution was collected. In a few cases, samples of urine voided on the morning following the infusion were collected. All urine samples were tested for hemoglobin by the benzidine test.

In four cases, venous blood samples were carefully drawn into syringes which had been wet with heparin solution. In each case a blood sample was obtained prior to infusion, another just before completion of the infusion, and a third sample seven hours after completion. The samples were promptly centrifuged, plasma was removed, and the hemoglobin concentration of each plasma sample was measured as described below.

Determination of hemoglobin in plasma. Oxyhemoglobin has a strong optical absorption maximum at 414 $\mathrm{m} \mu$, which conveniently permits the detection and estimation of low concentrations of hemoglobin. To correct for the variations among plasma samples in nonspecific optical absorption, due mostly to opalescence, optical densities were measured at $365 \mathrm{~m} \mu$, as well as at $414 \mathrm{~m} \mu$.
It was found that the difference between the optical densities at $414 \mathrm{~m} \mu$ and $365 \mathrm{~m} \mu$ was a linear function of hemoglobin concentration in the range of 0 to $20 \mathrm{mg}$. hemoglobin per $100 \mathrm{ml}$. of plasma. A working curve was prepared by determining this difference for samples of plasma to which known quantities of hemoglobin had been added. This method was not exhaustively tested, and is not proposed at the present time as a generally applicable method. It may, in the presence of interfering substances, be subject to positive errors but is quite unlikely to be subject to appreciable negative errors. A few of the plasma samples were analyzed by both this spectrophotometric method and by a chemical method (17), and the results obtained by the two methods were in good agreement.

The measurements were carried out in the following manner. To $2.0 \mathrm{ml}$. of buffered $(\mathrm{pH} \mathrm{7.4)} \mathrm{saline} \mathrm{solution}$ was added $1.0 \mathrm{ml}$. of the plasma sample and the mixture was well mixed. Optical densities were then measured in a $10 \mathrm{~mm}$. Corex cell at $414 \mathrm{~m} \mu$ and $365 \mathrm{~m} \mu$ using a Beckman model B spectrophotometer. From the differences in optical densities at these two wave lengths, the hemoglobin concentrations of the plasma samples obtained during and after the infusion were calculated and expressed as increases over that of the preinfusion plasma sample.

RESULTS

\section{Rabbit experiments}

Six experiments with unanesthetized rabbits were performed in which the solutions administered contained $5 \mathrm{Gm}$. each of glycerol and glucose and $0.9 \mathrm{Gm}$. sodium chloride per $100 \mathrm{ml}$. The quantities infused varied from $120 \mathrm{ml}$. to $175 \mathrm{ml}$. per rabbit, and were administered during periods varying from 60 to 90 minutes. No evidence of central nervous system irritation or any abnormal behavior was observed in any case. An elevation of rectal temperature of 1 to $2^{\circ} \mathrm{F}$. occurred in two cases, but these returned to preinfusion levels within two hours after infusion. The rabbits urinated copiously and all urine specimens were found to be free of hemoglobin. The rabbits were normally active immediately following the fluid administration and remained so. There was no evidence of any harmful effect having been caused by the intravenous administration of the glycerolcontaining solution.

In two additional experiments, $80 \mathrm{ml}$. and 100 ml., respectively, of the same 5 per cent glycerol solution were infused during a period of approximately one hour. Plasma samples were obtained, and their hemoglobin concentrations were determined as described above. In both rabbits, the 


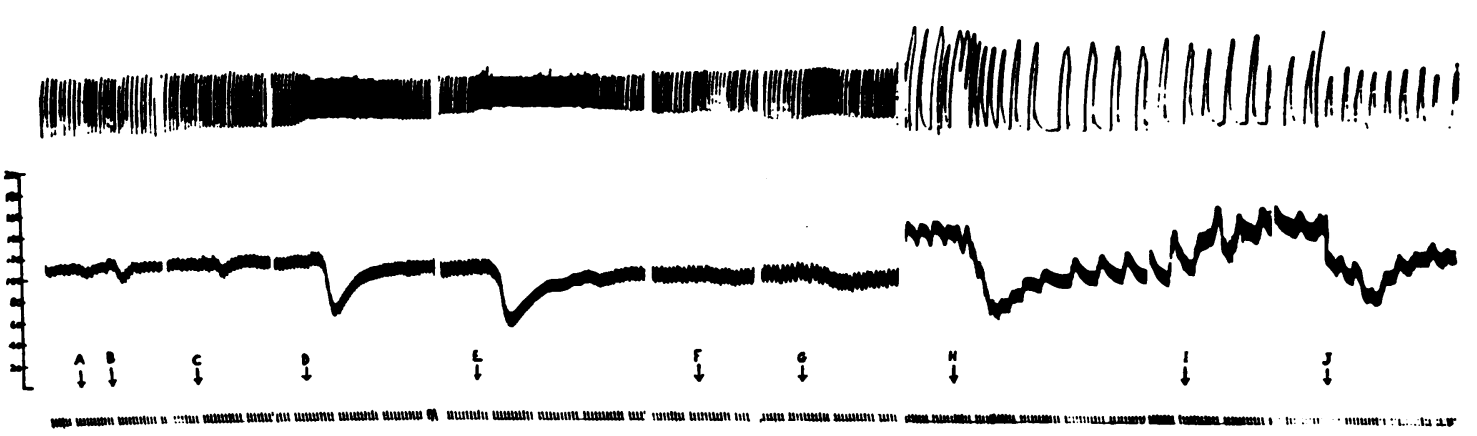

Fig. 1. Blood Pressure and Respiration of $10.1 \mathrm{Kg}$. Dog During Intravenous Administration of Glycerol Solutions

A. Five per cent glycerol- 5 per cent glucose- 0.9 per cent $\mathrm{NaCl}$ solution at $20 \mathrm{ml}$. per minute.

B. Same solution as in A, $20 \mathrm{ml}$. in 15 seconds.

C. Twenty per cent glycerol- 0.9 per cent $\mathrm{NaCl}$ solution, $10 \mathrm{ml}$. in 10 seconds.

D. Same solution as in C, $20 \mathrm{ml}$. in 15 seconds.

E. Fifty per cent glycerol- $0.9 \mathrm{NaCl}$ solution, $10 \mathrm{ml}$. in 10 seconds.

F. Nine-tenths per cent $\mathrm{NaCl}$ solution, $20 \mathrm{ml}$. in 15 seconds.

G. Five per cent $\mathrm{NaCl}$ solution, $20 \mathrm{ml}$. in 20 seconds.

Vagus nerves were cut between $\mathrm{G}$ and $\mathrm{H}$.

H. Fifty per cent glycerol- 0.9 per cent $\mathrm{NaCl}$ solution, $20 \mathrm{ml}$. in 20 seconds.

I. Same solution as in $\mathrm{H}, 4 \mathrm{ml}$. into carotid artery.

J. Same solution as in $\mathrm{H}, 10 \mathrm{ml}$. into descending aorta.

plasma hemoglobin concentrations of the samples taken near the end and shortly after infusion were higher than the preinfusion level by $5 \mathrm{mg}$. per 100 $\mathrm{ml}$. The samples taken near the beginning of the infusion and on the following day had hemoglobin concentrations which were not measurably different from the preinfusion levels (differences not greater than $2 \mathrm{mg}$. per $100 \mathrm{ml}$.).

\section{Dog experiments}

Three experiments with dogs under pentobarbital anesthesia were carried out. In one case, 50 $\mathrm{ml}$. of the 5 per cent glycerol- 5 per cent glucose- 0.9 per cent sodium chloride solution was injected intravenously during a 15 minute period prior to administration of pentobarbital. No signs of central nervous system irritation or abnormal behavior were observed following this injection. The infusion in a $12 \mathrm{Kg}$. anesthestized dog of a total of $200 \mathrm{ml}$. of this solution, during a $50 \mathrm{~min}$ ute period caused no change in blood pressure or respiration. The administration of this solution at the rather rapid rate of $20 \mathrm{ml}$. per minute had no significant effect on blood pressure or respiration. The infusion of $20 \mathrm{ml}$. of this solution in 15 seconds caused a small drop (about $16 \mathrm{~mm}$.) in blood pressure which returned to its previous level in less than one minute. Infusion of 0.9 per cent sodium chloride solution at this same rapid rate had no effect on blood pressure. These effects are shown in Figure 1, items A, B and F.

The infusion of 20 per cent glycerol- 0.9 per cent sodium chloride solution at the rate of about $6 \mathrm{ml}$. per minute caused no change in blood pressure or respiration. Giving $10 \mathrm{ml}$. in 10 seconds caused a small transient drop $(10 \mathrm{~mm}$.) in blood pressure and infusion of $20 \mathrm{ml}$. in 15 seconds caused a sharp drop $(50 \mathrm{~mm}$.) in blood pressure which returned to its previous level in about one minute (Figure 1, C and D). There was also an increase in respiratory rate. Similar effects of somewhat smaller magnitude occurred when 20 per cent glycerol in water was infused. When 50 per cent glycerol- 0.9 per cent sodium chloride solution was infused at the rate of $2 \mathrm{ml}$. per minute, small fluctuations in blood pressure were observed and when $10 \mathrm{ml}$. was infused in 10 seconds, blood pressure rapidly dropped $60 \mathrm{~mm}$., respiratory rate increased markedly, and both returned to previous levels in about two minutes (Figure 1, E).

To determine to what extent the effects observed with these glycerol solutions might be due 
to their hypertonicity, 5 per cent sodium chloride was infused intravenously. It was found that infusion of this hypertonic saline at the rate of $4 \mathrm{ml}$. per minute had no effect, and that $20 \mathrm{ml}$. given in 20 seconds produced a slight and relatively slow reduction in blood pressure (Figure 1, G).

The injection of glycerol solution, directly into a carotid artery of the dog with vagus nerves either intact or cut, had no significant effect on blood pressure or respiration. In a dog with cut vagus nerves, the intravenous infusion of a 50 per cent glycerol solution produced a sharp drop in blood pressure, similar to that produced in the dog with intact vagus nerves except that in the former case, the return of the blood pressure to its previous level was considerably slower (Figure $1, \mathrm{H}$ and I).

In one dog with vagus nerves cut, the injection of glycerol solution was made into the descending aorta, via a polyethylene catheter which had been inserted in the left carotid artery and advanced till its orifice was at about the level of the diaphragm. The injection here of $10 \mathrm{ml}$. of 50 per cent glycerol in 0.9 per cent sodium chloride solution produced a sharp drop in blood pressure which slowly returned toward the previous level (Figure 1, J).

Urine specimens collected at various times during the experiments with the dogs were all found to contain no hemoglobin.

\section{Human experiments}

Each of a series of 12 patients was given intravenously $50 \mathrm{Gm}$. of glycerol in a liter of solution. The observations made on these patients, both prior to and during the course of the infusions, are listed in Table I. It can be seen that, in most cases, blood pressure was little changed from the preinfusion level during the course of the infusion. In a few cases, there was a small rise in blood pressure, but no more than might be expected from the relatively rapid intravenous administration of any considerable amount of fluid to a group of older patients. In no case was there any change in cardiac or respiratory rate of appreciable magnitude. Body temperature showed no appreciable change, which might have been due to a reaction to the glycerol, for in no case was there an elevation of temperature of more than one degree. A small rise in body temperature might be expected as a result of the metabolism of the administered glycerol and glucose. Occasional small temperature elevations, which are probably due to pyrogens, are not unusual in any series of intravenous injections.

In most cases the infusions were entirely uneventful, insofar as subjective reactions are concerned. One patient remarked about a transient generalized feeling of warmth, another of nasal stuffiness of short duration, and another that her legs felt cold for a few minutes. There was no occurrence of headache, visual symptoms or dizziness. No cardiac irregularities were observed. That the infusions were completed without serious incident is indicated by the fact that in no case was it necessary to discontinue or interrupt the infusion before its completion. There was no complaint of pain at the site of injection, and no thrombosis of the veins which were used was noted.

In most cases, a moderate diuresis resulted from the infusions. In each case, one or more urine specimens were collected both during and after the infusion, and in some cases on the following day. All urine specimens in all cases were found to contain no hemoglobin.

Four additional patients were infused with a liter of solution containing $50 \mathrm{Gm}$. of glycerol in the same manner as were the other patients, except that samples were obtained for the determination of plasma hemoglobin concentrations. Two of the patients received solutions containing the glucose ( 5 per cent) and sodium chloride ( 0.9 per cent) as well as the glycerol, while in the other two cases, the sodium chloride was omitted. In all four cases, the subjective and objective reactions of the patients to the infusions were not significantly different from those observed with the other patients. The plasma hemoglobin concentrations of the samples taken just before completion of the infusions were higher than the preinfusion values by 3 and $8 \mathrm{mg}$. per $100 \mathrm{ml}$. in the two cases where the solutions infused contained salt, and by 4 and $10 \mathrm{mg}$. per $100 \mathrm{ml}$. in the two cases where the solutions did not contain salt. In all four cases, the plasma hemoglobin concentrations of the samples obtained seven hours after the infusion were not measurably different from the preinfusion levels.

In Patient 3, who had a pneumonitis and whose 
TABLE I

Intravenous administration of glycerol solutions* to human subjects

\begin{tabular}{|c|c|c|c|c|c|c|c|c|c|}
\hline \multirow{2}{*}{$\begin{array}{l}\text { Patient, } \\
\text { description and } \\
\text { diagnosis }\end{array}$} & \multirow{2}{*}{$\begin{array}{l}\text { Dura- } \\
\text { tion of } \\
\text { infusion } \\
\text { (hours) }\end{array}$} & \multicolumn{2}{|c|}{ Blood pressure } & \multicolumn{2}{|c|}{ Temperature $\left({ }^{\circ} \mathrm{F}.\right)$} & \multicolumn{2}{|c|}{ Pulse rate } & \multicolumn{2}{|c|}{ Respiratory rate } \\
\hline & & $\begin{array}{c}\text { Before } \\
\text { infusion }\end{array}$ & $\begin{array}{c}\text { During } \\
\text { infusion }\end{array}$ & Before & During & Before & During & Before & During \\
\hline $\begin{array}{l}\text { 1. } 55 \text { yr. male } \\
95 \text { lbs., } \\
\text { parotid } \\
\text { carcinoma }\end{array}$ & 6 & $90 / 70$ & $98 / 70-105 / 75$ & 100.0 & $98.8-100.0$ & 104 & 96-104 & 20 & $18-20$ \\
\hline $\begin{array}{l}\text { 2. } 75 \mathrm{yr} \text {. female } \\
110 \mathrm{lbs} \text {., } \\
\text { mammary } \\
\text { carcinoma }\end{array}$ & 5 & $145 / 85$ & $145 / 80-155 / 90$ & 99.0 & $99.0-100.0$ & 80 & $76-88$ & 20 & $20-22$ \\
\hline $\begin{array}{l}\text { 3. } 66 \text { yr. male } \\
120 \text { lbs., } \\
\text { pancreatic } \\
\text { carcinoma }\end{array}$ & 6 & $120 / 80$ & $120 / 70-140 / 80$ & & & 110 & $100-115$ & 30 & $26-30$ \\
\hline $\begin{array}{l}\text { 4. } 41 \mathrm{yr} \text {. female } \\
118 \mathrm{lbs} ., \\
\text { colon } \\
\text { carcinoma }\end{array}$ & 6 & $124 / 78$ & $114 / 64-124 / 78$ & & & 104 & $96-108$ & 20 & $20-24$ \\
\hline $\begin{array}{l}\text { 5. } 75 \mathrm{yr} \text {. female } \\
105 \text { lbs., } \\
\text { pancreatic } \\
\text { carcinoma }\end{array}$ & 4 & $116 / 60$ & $108 / 54-116 / 60$ & 98.6 & $98.6-98.6$ & 60 & $56-80$ & 20 & $18-20$ \\
\hline $\begin{array}{l}\text { 6. } 39 \mathrm{yr} \text {. female } \\
110 \mathrm{lbs} \text {., } \\
\text { mammary } \\
\text { carcinoma }\end{array}$ & 6 & $118 / 90$ & $110 / 78-130 / 80$ & 99.0 & $98.8-100.0$ & 84 & $80-100$ & 20 & $20-28$ \\
\hline $\begin{array}{l}\text { 7. } 56 \text { yr. female } \\
83 \text { lbs., } \\
\text { stomach } \\
\text { carcinoma }\end{array}$ & 4 & $110 / 60$ & $108 / 66-116 / 60$ & 98.4 & $98.6-98.8$ & 92 & $92-100$ & 20 & $20-22$ \\
\hline $\begin{array}{l}\text { 8. } 60 \text { yr. female } \\
170 \text { lbs., } \\
\text { malignant } \\
\text { melanoma }\end{array}$ & $3 \frac{1}{4}$ & $130 / 70$ & $128 / 70-146 / 88$ & 98.8 & $99.0-99.4$ & 68 & $72-80$ & 20 & $18-22$ \\
\hline $\begin{array}{l}\text { 9. } 66 \text { yr. female } \\
135 \text { lbs., } \\
\text { mammary } \\
\text { carcinoma }\end{array}$ & 4 & $90 / 70$ & $88 / 70-116 / 74$ & $100.2(\mathrm{R})$ & $100-101.2$ & 112 & $100-116$ & 28 & $26-28$ \\
\hline $\begin{array}{l}\text { 10. } 37 \text { yr. female } \\
147 \text { lbs., } \\
\text { mammary } \\
\text { carcinoma }\end{array}$ & $3 \frac{1}{4}$ & $108 / 70$ & $108 / 70-118 / 70$ & 99.4 & $98.6-99.8$ & 112 & $100-104$ & 20 & $18-20$ \\
\hline $\begin{array}{l}\text { 11. } 73 \text { yr. female } \\
110 \text { lbs., } \\
\text { mammary } \\
\text { carcinoma }\end{array}$ & $3 \frac{3}{4}$ & $145 / 90$ & $148 / 88-164 / 100$ & 98.8 & $98.8-98.8$ & 88 & $78-82$ & 18 & $18-20$ \\
\hline $\begin{array}{l}\text { 12. } 68 \text { yr. female } \\
\text { mammary } \\
\text { carcinoma }\end{array}$ & $3 \frac{1}{2}$ & $138 / 70$ & $120 / 64-138 / 70$ & 98.0 & $98.2-98.4$ & 100 & $96-104$ & 20 & $20-22$ \\
\hline
\end{tabular}

${ }^{*}$ In all cases except No. 9 one L. of solution which contained $50 \mathrm{Gm}$. of glycerol, $9.0 \mathrm{Gm}$. of sodium chloride and $50 \mathrm{Gm}$. of glucose was infused. In case No. 9 the sodium chloride was omitted.

chest was full of coarse râles, there was significant clearing of his lungs after the infusion, as judged by auscultation. This observation is noted as being of possible significance, only because of a report that glycerol has a bronchodilating action (18).

\section{DISCUSSION}

The results of the present study indicate that considerable amounts of glycerol in moderately dilute solution can be safely administered intravenously to animals and man. In the present study, the highest total quantity administered to man in 
terms of body weight is $1.2 \mathrm{Gm}$. per $\mathrm{Kg}$. For the rabbit, this value was higher than $2 \mathrm{Gm}$. per $\mathrm{Kg}$. and for the dog, higher than $3 \mathrm{Gm}$. per $\mathrm{Kg}$. These findings are not entirely in agreement with those of some previous studies in experimental animals. Some of the differences in results and conclusions are probably due to differences in the concentration and composition of the solutions administered, and to differences in rate, and the particular parenteral route of administration which were employed. It appears that most of the toxic effects previously reported were observed in cases where undiluted or very concentrated glycerol was injected. For example, Solomidès (14) reported that $1.0 \mathrm{Gm}$. per $\mathrm{Kg}$. of undiluted glycerol given intravenously to rabbits was uniformly fatal, but that the same quantity of glycerol previously diluted with an equal quantity of saline solution produced neither mortality nor morbidity. It would seem reasonable to conclude that, in this case, the toxic effects reported were due to the osmotic disturbances which the undiluted glycerol caused rather than to an inherent toxicity of the glycerol molecule. The data reported in the review paper by Deichmann (19) also suggest that severe dehydration and osmotic disturbances were very likely responsible for the noxious effects observed.

Cameron and Finckh (9) reported that in the rat, moderate intravenous doses of 50 per cent glycerol solution produced some hemolysis, and that large doses caused convulsions by dehydration. However, they found that large intravenous doses of a 20 per cent solution caused no hemolytic effects. They also reported considerable species differences in the occurrence of hemolysis; for example, in the rabbit they found no hemoglobinuria, even after intravenous injection of undiluted glycerol. These species differences may be related to rather large differences in the permeability to glycerol of the erythrocytes of the different species. That glycerol itself is not a hemolytic agent is indicated by the fact that large amounts of glycerol can be added to blood in vitro without producing any lysis as long as the ionic strength of the mixture is not markedly decreased (1). In the present study, the uniform absence of hemoglobinuria during and after the infusion of glycerol solutions in all three species demonstrates that no considerable amount of intravascular hemolysis occurs. However, hemoglobinuria is a relatively insensitive test for the occurrence of hemolysis, because of the renal threshold for hemoglobin. It is, however, evident, from the results of the direct measurement of plasma hemoglobin concentrations, during and after the infusion of glycerol solutions, that no more than a very slight amount of hemolysis occurs. Plasma hemoglobin concentrations in normal individuals are of the order of $5 \mathrm{mg}$. per $100 \mathrm{ml}$. (20). The increases in plasma hemoglobin concentration which were noted in the present study were in no case greater than $10 \mathrm{mg}$. per $100 \mathrm{ml}$, either during or after the administration of glycerol solutions. Increases of this magnitude might well occur during the infusion of more conventional intravenous fluids. There appears to be no published report on the effect of the routine administration of intravenous fluids on plasma hemoglobin levels.

Previous studies have disclosed that hemolytic effects were frequent after subcutaneous injection of glycerol solutions, but were absent or infrequent after intravenous administration. In nearly all cases, the solutions injected were markedly hypertonic. This difference in the frequency of occurrence of hemolysis, between subcutaneous and intravenous administration, might well be due to the fact that the osmotic effects of hypertonic solutions are minimal when given intravenously, because of the rapid dilution by the circulating blood. There is no evidence that glycerol reacts with the subcutaneous or other tissues to give rise to a hemolytic substance, but this possibility is not excluded. It should be remembered that the unintentional perivascular infiltration of a glycerol solution may produce some undesirable effects.

In the present study, no significant effects on blood pressure were observed in man or dog, except that in the dog very rapid intravenous injection of concentrated solutions (e.g., $10 \mathrm{ml}$. in 10 seconds of 50 per cent solution) produced transient hypotension. This is in contrast to the statement by Johnson, Carlson, and Johnson (5) that in the dog, "even a small dose of glycerol intravenously produces a transient fall in arterial pressure." It is possible that the hypotensive effects observed by these authors may have been due to an impurity in the glycerol which was used. In the present study, the transient hypotension produced by the rapid intravenous injection of concentrated glycerol solution seems most likely to 
be due to peripheral vasodilation. Glycerol might be expected to have a vasodilating action because of its chemical similarity to ethanol. That the hypotension is not due to an effect on the central nervous system is indicated by the absence of hypotension when glycerol solution was injected into a carotid artery. Reflex vagal slowing of the heart could not have been the cause of the hypotension, since the hypotensive effect persisted after cutting the vagus nerves. A depression of myocardial contraction by glycerol is not excluded, but seems unlikely because injection of concentrated glycerol solution into the descending aorta produced a prompt fall in blood pressure. Another possible cause of hypotension when intravascular hemolysis occurs is the release of nucleotides from the erythrocytes. It has been shown that these nucleotides have a potent hypotensive action (21). In the present study, no significant degree of intravascular hemolysis occurred, and thus it is very unlikely that the transient hypotension was due to release of nucleotides.

The previously reported occurrence of convulsions and other manifestations of central nervous system dysfunction $(9,12)$ were also quite possibly due to the severe osmotic disturbance, produced by the injection of quite concentrated solutions of glycerol. In the present study, where the tonicity of the administered solutions was not high enough to produce appreciable osmotic derangement, no signs of central nervous system irritation were observed. The reported occurrence of central nervous system irritation one or more days after injection of glycerol seems to be best explained by the tissue dehydration and electrolyte disturbance resulting from the diuresis which was produced (13).

The demonstration that glycerol can be safely administered intravenously in considerable quantity opens the way to the possible use of this substance as an intravenous nutritional agent. That glycerol is rapidly metabolized and gives rise to blood glucose is indicated by the findings that intraperitoneal injections of glycerol solutions in rabbits (22) and oral administration of glycerol to man (6) cause hyperglycemia. Furthermore, insulin convulsions in the rat were promptly relieved by the intraperitoneal injection of glycerol solutions (23). It has also been shown that glycerol solutions have an antiketogenic ef- fect when injected intraperitoneally in starved ketonemic rats (24). It is possible that glycerol is more efficiently utilized than is glucose, by individuals suffering from diabetes or other metabolic diseases. Glycerol has recently been used to stabilize fat emulsions, which are intended as intravenous nutritional preparations (25). Glycerol may also be a useful solvent in preparations of drugs for intravenous administration.

\section{SUM MARY}

The intravenous administration of solutions containing 5 per cent glycerol to experimental animals and to man has been found to cause no toxic or otherwise undesirable effects. Human subjects have been given intravenously $50 \mathrm{Gm}$. of glycerol in a liter of solution which contained, in addition to the glycerol, $50 \mathrm{Gm}$. of glucose and $9.0 \mathrm{Gm}$. of sodium chloride. No disturbances of cardiorespiratory or central nervous system function were observed, and no significant hemolytic effects occurred.

The previously reported toxic effects of parenterally administered glycerol have not been observed, and there are indications that these toxic effects were due to the osmotic disturbances produced by the injection of glycerol solutions of high concentration. In the dog, the rapid injection of concentrated solutions of glycerol produced a transient drop in blood pressure, and this was probably due to a peripheral vasodilating effect.

It is suggested that intravenously administered glycerol may be a useful nutritional agent.

\section{ACKNOWLEDGMENT}

Grateful acknowledgment is made to Dr. N. Henry Moss and Dr. Charles Smart for assistance with the human experiments, and to Dr. Domingo Aviado for helpful suggestions concerning the experiments with the dogs.

\section{REFERENCES}

1. Sloviter, H. A. Recovery of human red cells after prolonged storage at $-79^{\circ} \mathrm{C}$. Nature (Lond.) 1952, 169, 1013.

2. Mollison, P. L., Sloviter, H. A., and Chaplin, H., Jr. Survival of transfused red cells previously stored for long periods in the frozen state. Lancet 1952, 2, 501 .

3. Sloviter, H. A. A method for preparing thawed erythrocyte-glycerol mixtures for transfusion. Amer. J. med. Sci. 1956, 231, 437. 
4. Gidez, L. I., and Karnovsky, M. L. The metabolism of $\mathrm{C}^{14}$-glycerol in the intact rat. J. biol. Chem. 1954, 206, 229.

5. Johnson, V., Carlson, A. J., and Johnson, A. Studies on the physiological action of glycerol on the animal organism. Amer. J. Physiol. 1933, 103, 517.

6. Ferber, J., and Rabinowitsch, S. Increase in blood sugar following the ingestion of glycerol. Amer. J. med. Sci. 1929, 177, 827.

7. Anderson, R. C., Harris, P. N., and Chen, K. K. Toxicological studies on synthetic glycerin. J. Amer. pharm. Ass., sci. Ed. 1950, 39, 583.

8. Kopf, R., Loeser, A., and Meyer, G. Biologische Wirkungen der dreiwertigen Alkohole 1, 2, 4Butantriol und 1, 2, 3-Propantriol (Glyzerin). Naunyn-Schmiedeberg's Arch. exp. Path. Pharmak. 1951, 212, 405.

9. Cameron, G. R., and Finckh, E. S. The production of an acute haemolytic crisis by the subcutaneous injection of glycerol. J. Path. Bact. 1956, 71, 165.

10. Deichmann, W. Glycerol. Industr. Med. 1941, 10, Industr. Hyg. Sect. 2, 5.

11. Pfeiffer, C., and Arnove, I. Glycerol toxicity and hemoglobinuria in relation to vitamin C. Proc. Soc. exp. Biol. (N. Y.) 1937, 37, 467.

12. Schübel, K. Zur Pharmakologie des Glycerins. Naunyn-Schmiedeberg's Arch. exp. Path. Pharmak. 1936, 181, 132.

13. Zilversmit, D. B., and McCandless, E. L. Fate of intravenously administered glycerol. Proc. Soc. exp. Biol. (N. Y.) 1957, 95, 755.

14. Solomidès, J. Du mode d'action de la glycérine sur le bacille de Koch in vivo. C. R. Soc. Biol. (Paris) 1939, 131, 928.
15. Bowesman, C. Intra-arterial glycerin treatment of elephantiasis. Brit. J. Surg. 1938, 26, 86.

16. Todd, J. C., Sanford, A. H., and Wells, B. B. Clinical Diagnosis by Laboratory Methods. Philadelphia, Saunders, 1953, p. 101.

17. Creditor, M. C. The quantitative determination of plasma hemoglobin by the benzidine reaction. J. Lab. clin. Med. 1953, 41, 307.

18. Rocchietta, S. Azione broncodilatrice della glicerina. Minerva med. (Torino) 1954, 45, 1689.

19. Deichmann, W. Glycerol. Industr. Med. 1940, 9, Industr. Hyg. Sect. 1, 60.

20. Crosby, W. H., and Dameshek, W. The significance of hemoglobinemia and associated hemosiderinuria, with particular reference to various types of hemolytic anemia. J. Lab. clin. Med. 1951, 38, 829.

21. Deyrup, I. J. Release of adenine derivatives from mammalian erythrocytes following admixture of blood with strongly hypertonic solutions. Amer. J. Physiol. 1951, 167, 749.

22. Voegtlin, C., Thompson, J. W., and Dunn, E. R. Hyperglycemia produced by glycerol. J. biol. Chem. 1925, 64, 639.

23. Voegtlin, C., Dunn, E. R., and Thompson, J. W. Antagonistic action of certain sugars, amino acids and alcohols on insulin intoxication. Amer. J. Physiol. 1925, 71, 574.

24. Todd, C. M. The antiketogenic action of sorbitol in rats. Aust. J. exp. Biol. med. Sci. 1954, 32, 827.

25. Zilversmit, D. B., Salky, N. K., Trumbull, M. L., and McCandless, E. L. The preparation and use of anhydrous fat emulsions for intravenous feeding and metabolic experiments. J. Lab. clin. Med. 1956, 48, 386.

\section{SPECIAL NOTICE TO SUBSCRIBERS}

Post Offices will no longer forward the Journal when you move.

Please notify The Journal of Clinical Investigation, Business

Office, 333 Cedar Street, New Haven 11, Conn., at once when you have a change of address, and do not omit the zone number if there is one. 